\title{
SITUACION AMBIENTAL DE LA PROVINCIA DE BUENOS AIRES
}

\section{A. Recursos y rasgos naturales en la evaluación ambiental}

\author{
PRESENTACION E INTRODUCCION \\ Alejandro Aragón, Néstor O. Bárbaro, Jorge L. Frangi \\ Hugo L. López, José M. Sala, Isidoro B. Schalamuck \\ Mario E. Teruggi y Eduardo P. Tonni
}

AÑO 1-Nro. O - 1991

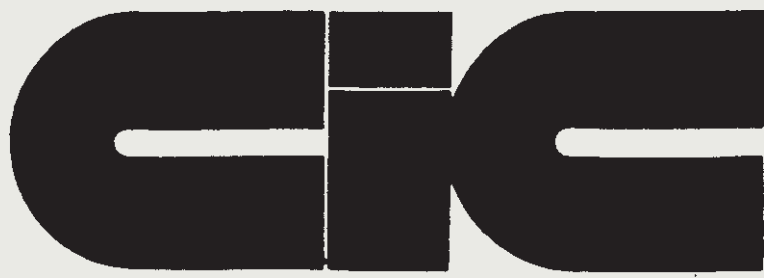

provincia de buenos aires comisión de investigaciones científicas calle 526 entre 10 y 11-1900 La Plata teléfonos 4379521737449581 


\section{Versión electrónica realizada por:}

Ing. Agr. Claudio della Croce

Junio de 2007, La Plata, Buenos Aires, Argentina 


\title{
SITUACION AMBIENTAL DE LA PROVINCIA DE BUENOS AIRES
}

\section{A. Recursos y rasgos naturales en la evaluación ambiental}

\author{
PRESENTACION E INTRODUCCION \\ Alejandro Aragón, Néstor O. Bárbaro, Jorge L. Frangi \\ Hugo L. López, José M. Sala, Isidoro B. Schalamuck \\ Mario E. Teruggi y Eduardo P. Tonni
}

AÑO 1 - Nro. O - 1991

Coordinación de la Serie: Dres.Hugo L. López y Eduardo P. Tonni Coordinación del Documento Presentación: Ing. Néstor O. Bárbaro

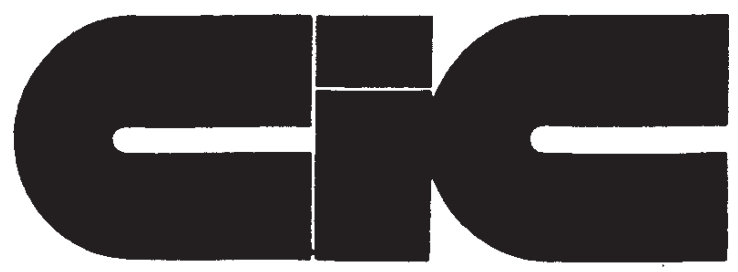

provincia de buenos aires comisión de investigaciones científicas calle 526 entre 10 y 11-1900 La Plata teléfonos 43795-217374-49581 


\title{
AUTORIDADES DE LA PROVINCIA DE BUENOS AIRES
}

\author{
GOBERNADOR \\ Dr. Antonio Cafiero \\ VICEGOBERNADOR \\ Lic. Luis María Macaya \\ MINISTRO DE GOBIERNO \\ Dr. José María Diaz Bancalari \\ MINISTRO DE ECONOMIA \\ Lic. Jorge Luis Remes Lenicov \\ MINISTRO DE OBRAS Y SERVICIOS PUBLICOS \\ Arq. Eduardo Quiñones \\ MINISTRO DE SALUD \\ Dr. Gines Gonzalez García \\ MINISTRO DE ACCION SOCIAL \\ Dr. José Luis Di Lorenzo \\ MINISTRO DE ASUNTOS AGRARIOS \\ Cdor. José María Vernet \\ DIRECTOR GENERAL DE ESCUELAS Y CULTURA \\ Agrim. Norberto Fernardino

\section{SECRETARIO GENERAL DE LA GOBERNACION} \\ Dr. Mario Cafiero
}

\section{AUTORIDADES DE LA CIC}

\author{
DIRECTORIO \\ PRESIDENTE \\ Ing. Néstor O. Bárbaro \\ VICEPRESIDENTE \\ Ing. Luis Pascual Traversa \\ DIRECTORES \\ Dr. Carlos Cañellas \\ Dr. Roberto Gratton \\ Dr. Mario Teruggi \\ SECRETARIO ADMINISTRATIVO \\ Dr. Antonio G. Redolatti
}




\section{PRESENTACION DE LA SERIE}

«Con sólo mirar ya sabemos que el ambiente está contaminado. Para qué estudiarlo?

«Qué pretendemos?. Que en este congreso sólo haya resultados científicos?».

Frases como estas, o similares, se escuchan frecuentemente en reuniones, coloquios o eventos diversos vinculados con la temática ambiental. Generalmente estas expresiones no surgen de especialistas en el tema sino de personas que por circunstancias especiales, se relacionan con el tema, tienen buenas intenciones y su discurso es escuchado por un auditorio también bien intencionado pero carente de la información y formación científica adecuadas.

Es posible que la escasa actuación pública de los profesionales especializados en el tema haya dejado espacio suficiente para que otras profesiones y otras personas y organizaciones, se hagan cargo de poner en vigencia un tema que ciertamente atrae y preocupa a toda la comunidad.

Por otra parte, es cierto que muchas obras oficiales se han realizado sin un adecuado estudio previo, lo cual ha provocado efectos no deseados en el entorno ambiental.

En suma, el tema del deterioro ambiental es real y se agrava continuamente. Pero aportar soluciones no es una cuestión de voluntarismo. Es necesario obtener un diagnóstico serio y fundamentado antes de proceder a tomar cualquier iniciativa que tenga incidencia directa sobre el ambiente, sea natural o ya modificado por la acción antrópica. El diagnóstico es, entonces, el punto de partida en toda acción destinada a evitar o a corregir situaciones ambientales que derivan en una pérdida o deterioro de la calidad de vida.

Diagnóstico. Ese es el tema básico. Tenemos ya un diagnóstico sobre la situación ambiental en la provincia de Bue nos Aires?. La respuesta es no, o al menos no en la medida deseada y necesaria. Hay elementos como para avanzar hacia ese diagnóstico?. Si, aunque parcialmente. Ya a fines de la década de 1950 y comienzos de 1960, se hicieron aportes importantes sobre el tema. Sin embargo estos aportes son, en general, dispersos, no integrados a una política general sobre los recursos naturales y el medio ambiente.

Las proximas décadas nos enfrentan a problemas ambientales por resolver y revertir. Esto hace necesario una participación más activa y mayor protagonismo de los profesionales de las ciencias naturales en los niveles de decisión. Si bien la 
comunidad científica realizó y realiza esfuerzos, los conocimientos logrados no han sido utilizados en proporción a lo obtenido. Existe gran cantidad de información dispersa, resultados de esfuerzos y recursos, la cual finalmente termina como un "producto o área gris del conocimiento» sin un adecuado traslado a la comunidad.

La serie que inicia la Comisión de Investigaciones Científicas de la provincia de Buenos Aires, es un intento - quizá aún desordenado - de brindar los elementos básicos para un diagnóstico. Estos podrán ser utilizados como una de las principales herramientas dentro de un plan global de gestión ambiental y de este modo iniciar uno de los caminos que permitan a Buenos Aires volver a tener el papel protagónico que le cupo en décadas pasadas en cuanto al manejo de sus recursos naturales.

Por otra parte esta es una demostración de que la comunidad científica - a pesar de situaciones muchas veces adversas - sigue produciendo, a bajo costo y con alta eficiencia, la información necesaria para la planificación y desarrollo del país.

La Plata, agosto de 1991.

Eduardo P. Tonni y Hugo L. López. 


\title{
SITUACIÓN AMBIENTAL DE LA PROVINCIA DE BUENOS AIRES
}

\author{
Documento \\ Presentación
}




\section{EL MARCO DE LAS POLITICAS AMBIENTALES}

\section{Néstor Omar Bárbaro}

\section{La Preocupación Ambiental}

La degradación ambiental y el deterioro de los recursos naturales han motivado, en las dos últimas décadas, la preocupación de los distintos países del mundo y de los organismos internacionales. Esta preocupación se esta instalando en todos los sectores de la sociedad y ocupa hoy un lugar predominante en la actividad de los gobiernas, sobre todo en los países más desarrollados.

La degradación y la contaminación de los suelos agríco las y urbanos, la eutroficación de las aguas superficiales y la contaminación de las subterráneas, el smog y el ruido en las zonas urbanas, la alteración del paisaje y la modificación y aún la erosión de la diversidad genética, son problemas que afectan con mayor o menor intensidad a todos los países.

Problemas como la contaminación de los recursos hídricos de uso sucesivo (los ríos), o de uso común (los mares), el efecto regional de las grandes represas, el efecto global de la tala indiscriminada de las selvas tropicales, el aumen to del efecto invernadero y el de la destrucción de la capa de ozono, las lluvias ácidas, etc., ocasionan vastos daños que trascienden las fronteras políticas.

La preocupación mundial por la situación ambiental generó hechos auspiciosos, como el inicio de acciones correctivas, la elaboración y ejecución de programas de investigación y vigilancia ambiental, y la inclusión de la dimensión ambiental en la formulación de programas de educación, difusión, salud, vivienda, desarrollo económico y cooperación internacional.

La búsqueda de consenso mundial para definir intereses comunes motivó la Conferencia de Estocolmo (1972), el llamamiento individual efectuado por dirigentes políticos (Perón, 1972), 
y la realización de informes globales como el Informe Brandt (Programme For Survival, 1980), el Informe Palme (Common Security, 1982) y el informe Brundland (Our Common Future, 1987).

Asimismo, se realizaron acuerdos sectoriales de cooperación internacional como la Convención Internacional Sobre el Comercio de Especies Amenazadas de Fauna y Flora Silvestre, CITES (1973), la Convención de Ginebra sobre Contaminación Ambiental Internacional (1979) el Protocolo de Montréal para la Protección de la Capa de Ozono (1988) y la Convención de Basilea sobre el Control de Residuos Peligrosos (1989).

Sin embargo, y a pesar del énfasis puesto en la Declaración del Medio Ambiente efectuada en la Conferencia de Estocolmo, y en las reuniones, conferencias y acciones ejecutadas tanto a nivel internacional cuanto por las distintas naciones, la situación ambiental de nuestro planeta se ha agravado.

En este sentido, debe tenerse en cuenta que los programas y propuestas ambientales a escala global, se hallan condicionados por una serie de factores, algunos de los cuales generan contradicciones entre discurso y acción.

En primer lugar, debe considerarse la magnitud de los intereses (culturales, económicos, sociales,...) en juego. Frente al peso real de otros intereses sectoriales, las decisiones sobre política ambiental tienen carácter relativo y muchas veces subordinado. En definitiva, los hechos ambientales son el reflejo de la cosmovisión social o de los intereses particulares de los grupos de poder político-económico y/o militar, que influyen de manera efectiva en la determinación de acciones que tienen consecuencias directas o indirectas sobre el medio ambiente.

En segundo lugar, se mantienen modelos de desarrollo y apropiación de los recursos naturales que son incompatibles con los objetivos explicitados en las políticas ambientales. Muchas de las medidas de control ambiental que se propugnan, o que habría que propugnar, ponen en tela de juicio muchos de los aspectos de los modelos de apropiación de recursos y de 
desarrollo vigentes, a la vez que limitan su puesta en practica.

En el orden económico y tanto en el marco de las economías de mercado como en el de las economías planificadas, los re cursos del ambiente fueron considerados como insumos de apro vechamiento gratuito, toda vez que derivan de una «res nulli» o cosa de nadie, en la que se había transformado, en la práctica, el patrimonio ambiental común, o «res populi».

Es evidente que el hombre no entendió, y en gran medida no lo entiende aún, que conservación de la capacidad productiva de los sistemas naturales es economía a largo plazo, sin desconocer, claro está, las implicancias económicas inmediatas del deterioro ambiental. Y esto más allá que el deterioro ambiental tenga efectos negativos directos sobre la actividad de quien lo genera (es el caso del agricultor cuando por crear riquezas llega a empobrecer su propio patrimonio), o que sobre la actividad de otros sectores, o sobre el conjunto social, generando en ese caso un costo social de difícil inclusión en las ecuaciones costo-beneficio.

Cuando se considera la cuestión costo-beneficio en el corto plazo, surge la evidencia de que muchas de las prácticas y procesos tecnológicos alternativos, aparecen como relativamente costosos, sea porque en la realidad lo son, sea porque en el análisis económico no se computa el costo de reparación que resulta del deterioro ambiental que surge. Esta forma operativa, aunque discutible, puede parecer válida cuando el daño ocasionado es de varios órdenes de magnitud menor a la sustentabilidad de un determinado sistema en particular, o de la naturaleza a escala global. La realidad muestra que muchas de las realizaciones locales y/o regionales han superado la capacidad de recuperación o mantenimiento de los sistemas artificializados.

En tercer lugar, en un mundo necesariamente interdependiente, la confrontación de intereses políticos, económicosy aún militares no siempre hace posible tener plenamente en cuenta los derechos y las necesidades de cada país y de la comunidad mundial en su conjunto. 
De esta manera, en el mismo momento en que los distintos foros mundiales, en general, y el Grupo de los Siete, en particular, exponen su preocupación por el efecto de la tala de las selvas tropicales sobre el clima global, ese mismo grupo de países (los Siete) participan de un esfuerzo bélico realizado, inexplicablemente, de una forma tal que - más alla de las consecuencias humanas desgarradoras - el ambiente se ve afectado a escala global a causa de «exterioridades militares» (incendio de pozos de petróleo, derrame de petróleo y contaminación de recursos hídricos), cuyas consecuencias son imprevisibles.

Otro ejemplo que debemos citar es el del condicionamiento al Tratado Antártico, impuesto por un país desarrollado, EE.UU., que dispone de la tecnología para la explotación de los recursos naturales de la Antártida. Lógico es suponer que si se acepta, en contra del sentido común, la explotación económica de la Antártida, debería previamente atenderse a las demandas territoriales de distintos países. (1)

Un tercer ejemplo de lo que acontece a escala mundial es la presencia de un impresionante arsenal nuclear que «cir cula» o se «asienta» aún en aquellas regiones que el Tratado de Tlatelolco declara libres de armas nucleares.

De la misma manera que los intereses políticos y militares pueden afectar, y de hecho afectan, la situación ambiental de terceros países, los intereses económicos actúan, en consecuencia, sea de manera directa (instalación de industrias sucias o de repositorios en países del Tercer Mundo) o indirecta (deterioro de los términos de intercambio y presión por el pago de los servicios de la deuda), provocando la necesidad de aumentar la presión sobre los recursos del ambiente.

(1) EE.UU. revisó posteriormente su postura y aceptó (3 julio de 1991) firmar el Protocolo de Protección Ambiental del Tratado Antártico. 
La falta de conocimientos científicos-tecnológicos es otro de los factores a considerar, en la medida en que la misma agrega incertidumbre a las propuestas que se efectúan sean sectoriales o globales. El cúmulo de intereses creados, sean estos internacionales o nacionales, hace difícil determinar en forma ecuánime, sobre la base de los conocimientos actuales, las causas de algunos efectos ambientales que preocupan a la comunidad internacional, y también los efectos que determinadas acciones tendrán sobre el ambiente. En este sentido es válido que formulemos interrogantes sobre las acciones ambientales sugeridas, para determinar si las mismas dilucidan la contradicción entre los modelos de desarrollo propuestos y medio ambiente, o si son apenas un paliativo para la situación planteada, entendiendo como tal un «remedio que cura las dolencias generalmente incurables, haciéndolas más llevaderas».

\section{Los Países Económicamente Desarrollados}

Mientras que para los países pobres la década anterior significó el estancamiento en su desarrollo y el endeudamien to externo-de allí su denominación de «década perdida»-, para los países industrializados ella significó la consolidación de un modelo de desarrollo del que derivaron sus propios problemas ambientales y, en gran medida, los problemas ambientales, en general, y la degradación de los recursos naturales, en particular, de los países no desarrollados.

Los países desarrollados iniciaron acciones de investigación, control y corrección de esta situación. Dichas acciones se basaron en la gravedad de sus propios problemas y de sus efectos a escala global, pero fueron posibles merced asu capacidad económico-financiera y, fundamentalmente, a la aparición de un nuevo paradigma tecnológico productivo que hizo a las economías de los países que lo ejecutaron menos subordinadas a los recursos naturales y a las tecnologías extractivas y de fuerte impacto ambiental.

En efecto, la aparición del nuevo paradigma estuvo motivada por factores como la 
necesidad de reducir a un mínimo la dependencia respecto de los recursos naturales, fundamentalmente los provenientes de otros países (crisis petrolera de 1973), la preocupación social para disminuir el impacto ambiental de las actividades económicas, y la disponibilidad de conocimientos tecnológicos. En forma constante se modifican las particularidades de los ciclos de producción acentuándose la tendencia a una nueva ocupación de los territorios, buscando el aprovechamiento óptimo de las ventajas comparativas (recursos humanos, recursos naturales, capacidad científica de centros universitarios).

\section{La Acción Gubernamental}

Los gobiernos de los países desarrollados han creado agencias u organismos ambientales, poniendo en práctica mecanismos de control y elaborando una legislación específica; es tán evolucionado, también, desde un principio general de «reparación» a una etapa donde «el principio de prevención» juega un papel importante.

Por otra parte, la extrema gravedad prospectiva ha hecho que distintas naciones colaboren en objetivos comunes. Es el caso de la Global Environment Facility (GEP) , creada con el auspicio de veinticinco (25) naciones y las Naciones Unidas, para promover el empleo de tecnologías adecuadas para la conser vación de energía y la limitación de la emisión de gases de invernadero, la preservación de áreas de alta diversidad biológica, la protección de aguas internacionales y la protección de la capa de ozono.

Según la Agencia de Protección Ambiental de los EE.UU (EPA), las acciones que se están efectuando permitirían que las emisiones de gases con efecto invernadero se reduzcan en el año 2000 a 2.332 millones de toneladas de carbono, cifra similar a la del año 1987 (2.328 millones de toneladas de carbono). 
Por su parte, el sector científico ha tenido y tiene una participación de fundamental importancia con relación al tema que nos ocupa. Los científicos, a quienes les cupo la responsabilidad de efectuar los primeros llamados de atención, se han constituido en miembros asesores de los distintos organismos y dependencias oficiales sectorialmente involucrados en el problema.

Los programas de investigación de los diferentes países muestran una importante orientación hacia temas ambientales.

En Suiza, las grandes áreas de investigación son el Hom bre, la Naturaleza y la Tecnología; en Alemania, el esfuerzo se orienta hacia Investigaciones Ecológicas, Tecnología del Medio Ambiente y Factores Metereológicos; en EE.UU., el Departamento de Energía (DOE) y la Universidad de California lanzaron el programa National Institute for Global Environment Change (NEGEC), para la coordinación y ejecución de proyectos en temas como Efecto Invernadero, Ozono y Uso de Energía y Contaminación.

\section{La Acción Empresaria}

El sector privado respondió a la preocupación de la sociedad y de los gobiernos, a las restricciones impuestas en el uso de elementos perjudiciales del medio ambiente y a los mecanismos de control, mediante el desarrollo y la realización de tecnologías de menor impacto ambiental y mediante la evaluación - con carácter reservado - de los efectos que ocasionan los respectivos productos o los ciclos de producción empleados. De hecho, las compañías petroleras y de producción de gas tienen sus propias redes de recolección de datos atmosféricos, geológicos y oceanográficos.

Pero, además, el sector empresario efectúa desarrollos tecnológicos con miras a participar en el mercado del control ambiental, la descontaminación y la puesta en práctica de tecnologías 
verdes. El número de empresas, la cantidad de cientí ficos y tecnólogos contratados y el esfuerzo financiero orientado a los problemas ambientales aumentan permanentemente. En Japón, las empresas efectúan, con el apoyo del Gobierno, el desarrollo de plásticos biodegradables, el reemplazo de los clorofluorocarbonados, tecnologías para absorber y utilizar $\mathrm{CO}_{2} \mathrm{y}$ biotecnología para eliminar derrames petroleros.

Si bien la participación empresaria es un hecho de suma importancia para la resolución de los problemas ambientales, la misma merece una consideración basada en el hecho que la complejidad de las causas de un determinado efecto ambiental permite múltiples acciones correctivas. El riesgo para la comunidad internacional, en general, y para los países que no disponen de capacidad propia de evaluación, investigación, y desarrollo tecnológico, en particular, es que se otorguen prioridad a aquellas decisiones que dependen de determinadas tecnologías o, por el contrario, encubran otras.

En otro orden de cosas, los países desarrollados están efectuando gestiones con los países no desarrollados, con miras a lograr la sanción, en cada país, de Leyes de Patentamiento que reconozcan los derechos de las empresas sobre sus propias innovaciones. Más allá de la discusión sobre si el patentamiento debe abarcar productos y procesos, y sin desconocer el derecho a las ganancias de quien innova a partir de su propia inversión, queda, en relación a la situación ambiental, un tema a considerar.

En efecto, los compromisos que se están asumiendo a nivel mundial, significan el reemplazo de tecnologías de fuerte impacto ambiental (gases clorofluorocarbonados, por ejemplo),por otras de menor impacto. Estas últimas tecnologías podrían estar sujetas a gravámenes de tal magnitud que limitarían su empleo en los países no desarrollados, acentuándose la tendencia a aumentar la brecha que los separa de los países desarrollados.

De esta forma, si por una parte se haría innaccesible el modelo de desarrollo implementado por algunos de los países actualmente desarrollados (Japón, por ejemplo), en razón de que se 
restringe la posibilidad de «aprender copiando», por la otra, la escasa capacidad innovadora de estos países en rela ción a la capacidad individual o asociada de los países ricos (CE : Programa Eureka), hace que los primeros corran el riesgo de implementar desarrollos técnicos o innovaciones a partir de sus propios recursos naturales (incluyendo germoplasmas) cuando las grandes empresas nacionales o multinacionales ya tengan reserva de mercado.

En cambio, no se les reconoce a los países no desarrollados y a pesar de los esfuerzos de la FAO, el derecho a percibir el cobro del material genético de sus territorios que es utilizado por empresas de los países ricos para sus propios planes de mejoramiento genético.

Por otra parte, es importante destacar que productos y procesos prohibidos en los países desarrollados han sido exportados y / o aplicados en países no desarrollados. Lo mismo sucede con la utilización de repositorios para la acumulación de residuos peligrosos, sean estos rezagos o exterioridades de procesos productivos efectuados en países con fuerte control ambiental.

Esta modalidad se contrapone con el accionar de empresas internacionales que actúan exportando y extendiendo a paí ses no desarrollados tecnologías aptas. Estas empresas, al incluir en sus propios costos de producción los que derivan de la protección ambiental, tienden a exigir a los gobiernos de los países del Tercer Mundo que extiendan el control ambiental a las empresas que ocupan su misma franja en el mercado nacional o internacional, con el objeto, claro está, de evitar lo que consideran subsidios encubiertos.

\section{Responsabilidad Ambiental}

En definitiva, las causas, y por lo tanto la solución de los problemas ambientales globales, involucran a la totalidad de los países, sean estos ricos o pobres. Sin embargo, es necesario 
reconocer la participación relativa que tiene ca da grupo de países en el deterioro del ambiente común. Consi derando el caso específico del aumento del efecto invernadero, debe reconocerse que el 90\% de dióxido de carbono emitido proviene del consumo de combustibles fósiles efectuados, en los países ricos, para obtener energía, y que la mayor parte de los compuestos clorofluorocarbonados (responsables, junto al dióxido de carbono y otros gases, del efecto invernadero) son producidos y exportados por los países ricos.

A los países desarrollados les cabe una gran responsabilidad en la búsqueda del consenso y de los mecanismos a implementar para que la humanidad tenga un futuro sustentable, comenzando, claro está, por frenar el propio despilfarro de recursos del ambiente, ocasionado por un individualismo y un afán de lucro económico desmedidos.

\section{Los Países no desarrollados}

\section{La situación Ambiental}

Los problemas ambientales de los países no desarrollados no obedecen únicamente a las derivaciones del propio desarrollo, sino, también y fundamentalmente, a la extensión de la pobreza, al deterioro de los términos de intercambio, a la deuda externa, y a la marginación de amplios sectores sociales.

En términos sociales, la calidad de vida de amplios sectores de la población se ve afectada por problemas de empleo, salud, alimentación, educación, vivienda y servicios. Pero además, tanto para los sectores de menores recursos como para los sectores pudientes, la calidad de vida se ve afectada por el deterioro ambiental.

Los sectores rurales no tienen acceso a servicios básicos. Lo mismo sucede en los grandes conclomerados urbanos, donde habitan los sectores desposeídos, o aún marginados del 
desarrollo económico. Dichas zonas no tienen acceso a servicios básicos (incluyendo agua potable y red cloacal), están sujetas a la imprevisibilidad de factores ambientales (zonas bajas, laderas friables...), sufren las consecuencias del mal desarrollo industrial y urbano de otros sectores sociales (urbanización en zonas fabriles, presencia de desechos y efluentes industriales y domiciliarios...). Los últimos estudios efectuados por la Comisión Económica para América Latina (CEPAL) muestran la tendencia actual a la disminución del ingreso en los sectores medios y bajos de las grandes ciudades latinoamericanas, incluyendo, claro está, a Buenos Aires.

Los «intereses difusos» existentes con relación a la situación ambiental no han encontrado aún, en muchos países no desarrollados, los canales de expresión y fijación de políticas ambientales adecuadas.

En términos ambientales, son moneda corriente la falta de planificación, la insuficiencia de servicios, el uso de tecnologías inadecuadas, la carencia de herramientas de control, el insuficiente o nulo reciclaje de residuos, las inadecuadas ecuaciones de uso de los recursos hídricos y energé ticos; y la situación se agrava permanentemente.

En términos de recursos naturales, que es el elemento central del presente trabajo, la situación es sumamente com pleja.

La participación en el comercio mundial, de acuerdo con el esquema de división internacional del trabajo vigente hasta los inicios de la actual revolución tecnológica, significó la «especialización» con relación a los recursos naturales utilizados, a la vez que potenció la «monoproducción» en la forma de uso de dichos recursos. Los recursos fueron visualizados menos como una potencialidad en sí misma, que como una «posibilidad» de acceder a la colocación de determinados productos en el mercado internacional.

Desde el punto de mira de los recursos naturales renovables, cuando las actividades económicas realizadas se basaron en la extensión o el desarrollo de modelos productivos acordes 
con la capacidad de uso de los ecosistemas naturales, se generaron situaciones de ocupación territorial que permitieron sistemas de producción sostenida, los cuales, claro está, no estuvieron exentos de causar deterioro en los recursos naturales. Tal fue el caso de la producción agropecuaria realizada en las regiones templado-húmedas del territorio argentino, que ocasionó la modificación de la diversidad genética, iniciada, históricamente, por el empleo de un nicho ecológico subutilizado: el de los grandes mamíferos. Nuestra región templado-húmeda, la pampeana, fue y es aún sinómino de producción sostenida y generación de riquezas. En contrapartida, la región está afectada por procesos de degradación graves (erosión de suelos, eutroficación de cursos hídricos, contaminación de aguas subterráneas, etc.), pero potencialmente controlables.

Cuando las actividades económicas se efectuaron con modelos inadecuados a las características y particularidades del ambiente, o en razón de objetivos únicos de lucro inmedia to, o generaron situaciones de ocupación territorial inesta bles, con pérdida o deterioro de determinados recursos naturales y con alteración de funciones ecológicas reguladoras. Es el caso de las regiones áridas y semiáridas que cubren la tercera parte de la superficie del planeta. Un porcentaje sig nificativo de pobladores de los países pobres vive en zonas áridas y semiáridas. En dichas regiones, la desertización, en tendiendo como tal «cambios ecológicos que privan a la tierra de su capacidad para sostener la agricultura y las comunidades», se extiende permanentemente.

La desertización fue reconocida como un problema a escala global durante el Simposio sobre Desertización efectuado por Naciones Unidas en 1977. La reconversión de dichas regiones exigirá enormes recursos económicos y financieros extrarregionales, como lo señala el Análisis de las Tendencias en América Latina y el Caribe (Naciones Unidas - Programa para el Medio Ambiente). 
En la Argentina, las regiones áridas y semiáridas cubren las dos terceras partes del territorio. En las mismas sólo se efectuaron actividades económicas extractivas, con excepción de los oasis de regadío.

En la estepa patagónica se efectuó una economía extractiva a partir de la ganadería ovina. La disminución del número de ovinos en la región estuvo en las últimas décadas relacionada, entre otros factores, con la degradación del recurso utilizado (el pastizal), con los procesos de erosión y desertización producidos, la falta de conocimientos y tecnologías para revertir la situación y, fundamentalmente, con la extrema fragilidad del ecosistema empleado. En las regiones áridas y semiáridas subtropicales, la economía extractiva se basó en el recurso forestal y en el pastizal. El recurso forestal fue asumido como no renovable, y explotado en razón de necesidades del mercado internacional (producción de tanino a partir del quebracho), del mercado nacional (leña, carbón, construcciones civiles urbanas y rurales), y de la infraestructura (ferrocarriles). La riqueza faunística de dichas regiones, y de otras, produjo un comercio singular, y no controlado, basado en la extracción de una riqueza constituida por especies a las que «fácilmente» se las tipificó «plaga».

Las regiones áridas y semiáridas subtropicales no fueron ni cultural ni económicamente consideradas desde el punto de mira de un desarrollo sustentable, sino en la medida en que eran susceptibles de permitir la extensión de modelos productivos propios de las regiones templado-húmedas. De hecho, muchas de las especies, y aún los ecosistemas, que fueron explotados económicamente, no tuvieron el apoyo sostenido del conocimiento científico, como lo demuestra la evaluación del financiamiento efectuado, en la década del 70, por el Programa Nacional de Recursos Naturales de la SECYT.

En los países pobres existen aún regiones vírgenes. Tal es el caso de las selvas tropicales, consideradas por su importancia, tanto con relación al clima global como en lo relativo a la 
biodiversidad que continen. Según algunos estudios la forestación sería responsable de la emisión del 15 al 30 \% del $\mathrm{CO}_{2}$ emitido a la atmósfera y contribuyendo en forma importante al aumento del efecto invernadero.

En el caso específico de las selvas tropicales están en juego numerosos intereses. Por un lado, los gobiernos de las naciones ricas proponen el mantenimiento de las mismas como reserva mundial de la biósfera; por el otro, grupos de intereses económicos de esos mismos países y de los países no desarrollados presionan para su explotación económica. Pero, además, los gobiernos de los países con selvas tropicales se hallan ante el dilema de conservar un bien natural o emplearlo para su propio desarrollo económico. Existen también el interés y la necesidad de supervivencia de los pobladores de la región.

\section{Las Acciones Ambientales}

En otro orden de cosas, los países menos desarrollados han iniciado la reconsideración de su situación ambiental, con importantes logros para determinados sectores de su respectivos territorios, sin que esto implique desconocer el agravamiento de la misma en otros sectores.

Como hechos positivos se puede mencionar la reducción de la superficie selvática deforestada anualmente en Brasil; los sistemas de prevención de la contaminación aplicados en grandes ciudades latinoamericanas; el control de la disposición de relaves de las empresas de cobre, en Chile; la ejecución de tecnologías conservacionistas en el sector agropecua rio....etc.

Estas acciones, aún puntuales, se basan tanto en una mayor toma de conciencia de la dirigencia de los respectivos países cuanto en la decidida participación de los grupos ambientalistas de la región.

En la Argentina existen casos en los cuales la acción de grupos ambientalistas produjo hechos que beneficiaron a la comunidad, como la prohibición de uso del agente naranja (de 
foliante prohibido en los países desarrollados) y la prohibición de capturar y exportar especies de la fauna autóctona.

Las constituciones de países como Brasil y Chile declaran el mantenimiento de condiciones ambientales adecuadas como un derecho de la comunidad nacional; el tema ambientales incluido en las relaciones bilaterales (el Tratado con Uruguay, firmado en 1974, prevé acciones comunes para evitar y controlar la contaminación del Río de la Plata) y multilaterales (Primera Reunión Ministerial entre la Comunidad Europea y el Grupo de Río; Luxemburgo, 1991); los parlamentarios de las distintas regiones forman foros regionales en los cuales el tema ambiental adquiere importancia (Declaración del Parlamento Latinoamericano).

Finalmente, los distintos países han creado organismos específicamente dedicados a la temática ambiental y desarrollaron programas de investigación orientados al conocimiento de diferentes aspectos del tema que nos ocupa.

\section{Desarrollo y Medio Ambiente}

Sin embargo, y a pesar de los hechos mencionados, los países menos desarrollados se enfrentan, sistemáticamente, con factores que restringen sus posibilidades de transformación. El problema fundamental de estos países es el desarrollo y la solución de la situación de pobreza y de marginación de importantes sectores sociales.

Desde el punto de mira ambiental, en un informe del Fondo de Población de Naciones Unidas, se advierte que el crecimiento de la población, unido a la pobreza, ocasiona una gran presión sobre los recursos del ambiente, en razón de necesidades de alimentos, vivienda y combustibles. Las proyecciones efectuadas permiten prever, para el año 2010, un aumento de población de aproximadamente 1800 millones de personas en los países en desarrollo y, para el mismo período, un aumento de 100 millones de personas en los países desarrollados. 
Además, se deben considerar los términos de la relación económica con los países desarrollados. La situación de endeudamiento externo, el deterioro de los términos de intercambio y las políticas proteccionistas mediante las cuales los países desarrollados subsidian su producción, compiten con el desarrollo económico y potencian la acción regional sobre los recursos del ambiente.

Más allá de las declaraciones, la situación planteada parecería agravarse en forma permanente. En el caso específico del proteccionismo, los países desarrollados sostienen y subsidian, entre otros, la producción primaria en sus propios territorios, la que muchas veces se efectúa en base a grandes cantidades de agroquímicos, agravando por ende sus propias situaciones ambientales. La Organización para la Cooperación y el Desarrollo Económico (OCDE) informó que en 1990 los subsidios a la producción agropecuaria de los países desarrollados se incrementaron, respecto de 1989, en un $12 \%$. Pero, evidentemente, los subsidios no se orientan únicamente a las producciones primarias, ocasionando, de esta manera, enormes perjuicios a los países no desarrollados.

Algunos pensadores y políticos de los países desarrollados llevan a la mínima expresión posible las diferencias entre las respectivas situaciones socio-económicas. En contrapartida, son estas diferencias las que hacen que muchos pensadores no desarrollados sean cautelosos o aún soslayen la cuestión ambiental. Es evidente que, a veces, una actitud de cautela realista permite encubrir intereses sectoriales que especulan con la posibilidad de «socializar» los costos ambientales de sus realizaciones económicas. En este sentido, no se puede ni se debe admitir que prácticas productivas realizadas de acuerdo con los marcos impuestos por la economía de mercado, utilicen el deterioro ambiental como una ventaja comparativa.

En última instancia, no es el desarrollo en sí mismo el que presupone, como hecho fatídico, la degradación ambiental, sino los modelos que se utilizan. 
La marginación y la pobreza siguen siendo el tema fundamental, a partir del cual es posible plantearse si la cuestión ambiental se puede transformar en el límite del crecimiento, cuando la misma afecto necesidades básicas no satisfechas de las poblaciones locales.

Por otra parte, es evidente que la apropiación de los recursos naturales debe hacerse de acuerdo con la posibilidad que brinda, en particular, cada situación ambiental; a esto se refiere el concepto de «desarrollo sostenido», máxime si se tiene en cuenta que las poblaciones marginales tienen acceso a la ocupación de regiones extremadamente lábiles y con escasa infraestructura de servicios.

En este sentido, para los países pobres, desarrollo, disminución de la situación de pobreza y de sus efectos y medio ambiente forman parte de la misma problemática global. De hecho, el colonialismo y el sometimiento del hombre por el hombre produjeron tanto la destrucción de culturas y modelos ambientales adecuados, como la degradación del ambiente.

\section{Aprovechamiento de los recursos naturales: La revolución verde}

Los modelos empleados para el aprovechamiento de los recursos naturales tendieron a minimizar las diferencias y singularidades propias de cada región, en razón de maximizar la rentabilidad basada en la obtención de determinados productos. Pueden ser definidos como reduccionistas y culturalmente sesgados en la medida en que su extensión no tuvo en cuenta ni la totalidad de posibilidades económicas ni las particularidades culturales de la población propia del país o la región en la cual se implementaron.

La llamada Revolución Verde es, quizá, el mejor ejemplo de lo que decimos. Presentada 
en la década del '70 como panacea universal llamada a resolver los acuciantes problemas del hambre en el mundo, se basó en la utilización, en los sistemas de producción agrícola, de subsidios energéticos derivados, directa o indirectamente, de los combustibles fósiles, en la extensión de unas pocas especies vegetales y en el empleo del riego.

Si, por una parte, la Revolución Verde no logró alcanzar los objetivos presentados, por la otra, ocasionó o extendió problemas que afectantanto a la población como al ambiente. Entre los problemas que afectan a la población se debe resaltar que se obtuvieron «aumentos engañosos» - derivados de la selección y el mejoramiento masal- en detrimento de la capacidad nutritiva de los productos primarios (muchas de las variedades o híbridos utilizados, producen granos de baja calidad cuando se los cultiva sin el acompañamiento de fertilizantes) y que, además, dichos productos pueden presentar residuos de substancias nocivas para el hombre.

La aplicación de este paquete tecnológico produjo la degradación de importantes recursos naturales, sea por las características intrínsecas de la tecnología en sí misma, como es el caso de los agroquímicos, sea por la extensión de su uso sin considerar la singularidad de cada situación ambiental. La intensificación del uso del suelo a través de la modalidad de la doble cosecha, posible por la presencia de variedades e híbridos de ciclo corto y por la utilización masiva de agroquímicos, significó una tendencia a la degradación de los suelos causada por el laboreo intensivo y por relegar a segundo plano la importancia de la materia orgánica edáfica. En este caso específico, el uso de fertilizantes nitrogenados permitió suplir una de las funciones de la materia orgánica, provi sión de nitrógeno, pero no las funciones referidas a estructura del suelo y retención de agua.

La implementación intensiva del modelo productivo de la Revolución Verde puede afectar 
la capacidad reguladora de los sistemas naturales, y producir la dependencia en determinados insumos, hecho este que ocasiona, aún en el corto y mediano plazo, modificaciones en la relación costo-beneficio, además, claro está, de afectar a los recursos del ambiente induciendo pérdidas económicas indirectas. Tal es el caso del uso indiscriminado y masivo de biocidas, los que a la vez de eliminar organismos nocivos para la producción agrícola, eliminan a sus depredadores naturales.

Además, entre el 80 y el $90 \%$ de los productos vegetales consumidos por el hombre, provienen de una decena de especies. Si por una parte no se utilizó la diversidad genética natural - la que aún no fue evaluada en su totalidad -, por la otra se descartaron, a través de distintos mecanismos y por diferentes causas, especies y variedades utilizadas por las culturas aborígenes, las que al decir del Ing. Lorenzo Parodi constituían una singular reserva de importancia tanto ecológica como económica.

Es precisamente en la época durante la cual la Revolución Verde se extiende, cuando se efectuan importantes llamados de atención sobre el uso indiscriminado del ambiente. En Informe al Presidente (EE.UU., 1977) se afirma que el aumento de la productividad obtenida por el empleo de subsidios energéticos encubre el deterioro de recursos naturales de uso agrícola como el suelo.

En última instancia, implementaciones tecnológicas como la Revolución Verde, tienden a ser eficaces, en la medida que buscan aumentar la producción, pero no son eficientes en la medida en que los aumentos obtenidos tienen una relación energía obtenida/energía subsidiada baja, subutilizando determinados recursos naturales y deteriorando otros.

Pero la Revolución Verde ha implicado también consecuencias que afectaron la interdependencia entre las naciones y a la vez significaron cambios en la renta de los distintos sectores sociales. 
Permitió en el seno de los países desarrollados, la obtención de excedentes agrícolas, los que apoyados por subsidios económicos, distorsionan el mercado internacional. Por otra parte generó problemas en los sectores campesinos de países como la India, que no pudieron afrontar los costos financieros que implica el uso de insumos extraprediales y, además, soportaron un impacto cultural para el que no estaban preparados. En definitiva, se produjo mayor concentración de la riqueza, mayor marginalidad y, en forma indirecta, mayor presión sobre los recursos naturales de los países del Tercer Mundo.

\section{El Cambio Tecnológico}

Las actuales transformaciones y sus tendencias futuras, muestran la posibilidad de disminuir en el mediano plazo, si no el impacto global sobre el ambiente, al menos el impacto implícito de las tecnologías empleadas.

A nivel mundial, la tercera revolución industrial se basa, fundamentalmente, en las innovaciones efectuadas en los sectores del complejo electrónico e informático, la biotecnología y los nuevos materiales, sin olvidar las innovaciones referidas al uso, generación y conservación de la energía.

El desarrollo de nuevos materiales permite reemplazar determinados metales por otros, o bien por productos cerámicos, o por compuestos plásticos. El aluminio, por ejemplo, puede ser sustituido por compuestos plásticos y papeles, ya la vez sustituir minerales como el zinc, el niquel, el cobre y otros. Pero además, existe la tendencia a aumentar el reciclaje de materiales y a utilizar procesos biotecnológicos, como la lixiviación bacteriana, para optimizar los procesos de extracción y recuperación minera. 
La biotecnología, por su parte tiene una importancia fundamental tanto en la producción agropecuaria cuanto en la utilización interespecífica de la materia prima obtenida. En el primer caso, la ingeniería genética permitirá acelerar la obtención de cultivares resistentes a determinadas plagas o a los efectos de estrés ambiental (sequías, heladas); el cultivo de tejido es una herramienta fundamental, toda vez que permite la multiplicación de determinados individuos, para el mejoramiento vegetal en razón de la demanda de los mercados y / o de las particularidades del ambiente. En el segundo caso, se está accediendo al reemplazo de determinadas materias primas por otras. Tal es el caso de la sustitución del azúcar por edulcorantes derivados del maíz (fructuosa).

Ahora bien, estas nuevas tecnologías son impulsadas tanto por las restricciones impuestas al uso de los recursos del ambiente, cuanto por la baja rentabilidad de las innovaciones sobre las tecnologías del paradigma anterior. La rentabilidad empresaria es, evidentemente, uno de los factores que impulsa los nuevos desarrollos tecnológicos.

Desde el punto de vista de los países menos desarrollados la aparición de un nuevo paradigma tecnológico tiene, como lo hemos apuntado oportunamente, consecuencias importantes. Por una parte, constituye una herramienta para crear y consolidar modelos de desarrollo y apropiación de recursos naturales ambientalmente sustentables. Por la otra, implica el riesgo de aumentar la brecha entre países ricos y países pobres y, en el seno de cada país, entre aquellos sectores que disponen de capacidad económica, financiera y cultural y los que no la poseen.

Las nuevas tecnologías permitirían aprovechar más eficientemente - eficiencia económica y también ecológica -, los recursos naturales, incluyendo el empleo de recursos no utilizados en el paradigma masivo anteriormente implementado. En contrapartida, el uso de nuevas tecnologías transforma el flujo internacional de materiales y productos - los economistas hablan 
de la tendencia hacia una «economía desmaterializada» - y modifica el valor relativo de las ventajas comparativas a cada país. En efecto, las ventajas comparativas estáticas, como los recursos naturales, tienden a perder su peso relativo ante ventajas comparativas dinámicas como la capacidad innovadora. Esta capacidad innovadora se refiere tanto al empleo de nuevas tecnologías cuanto a la utilización adecuada de tecnologías propias del paradigma anterior. En definitiva, la transformación de un paradigma en otro será paulatina, coexistiendo nuevas tecnologías con tecnologías tradicionales, potenciando la rentabilidad de estas últimas.

En este sentido, es importante destacar que el empleo de nuevos conocimientos y nuevas tecnologías puede transformarse en el elemento que dinamice el desarrollo de las llamadas tecnologías convenientes o adecuadas, las que tienden a ser menos impactantes, a la vez que utilizan en forma racional los recursos naturales y humanos locales y regionales. La biotecnología, por ejemplo, puede servir al mejoramiento y la tipificación de productos provenientes de especies utilizadas en las agriculturas y ganaderías aborígenes o permitir la introducción de especies regionalmente adecuadas.

Por su parte, el empleo de nuevos materiales afirma la posibilidad de utilizar fuentes energéticas alternativas, con la disminución del impacto ambiental propio de algunas de las fuentes de energía (combustibles fósiles, hidráulicas), o el riesgo implícito en otras (energía nuclear). La biotecnología, evidentemente, es también una herramienta para cambiar la ecuación energética actual (combustibles de origen vegetal).

En última instancia, no importa tanto la herramienta tecnológica utilizada para producir un determinado bien, sino las efeciencias económica y ecológica del ciclo de producción y la calidad del bien producido. El hecho definitorio es el de poseer la capacidad de discernir sobre la herramienta tecnológica que, en cada caso particular, debe ser empleada. El empleo y la extensión masiva de tecnologías, aún las ambientalmente aptas, puede, cuando no se tienen en 
cuenta las particularídades regionales, producir graves perjuicios al ambiente.

\section{Elementos para una Política Ambiental}

Está concluyendo la etapa durante la cual el desarrollo de los conocimientos y de las tecnologías resultantes, permitían suponer que a la naturaleza se la podía dominar y modelar como si fuera materia inerte. Los efectos que derivan de los mecanismos de acción - reacción, por una parte, y el empleo de los mismos conocimientos científicos tecnológicos que pen-samos, nos ayudarían a modificar a nuestro antojo los sistemas naturales, por la otra, nos muestran que el objetivo de la sociedad deberá ser, no la dominación, sino la adaptación inteligente, con miras a lograr el ambiente que satistaga plenamente las necesidades del hombre. Y nos estamos refiriendo, claro está, a las necesidades tanto físicas como psíquicas.

En este sentido, la cuestión ambiental no debe ser planteada, y por lo tanto resuelta, únicamente en los términos utilitarios de una civilización planetaria que enfrenta límites físicos cuya magnitud real desconoce. Antes bien, una propuesta ambiental seria, por lo tanto viable, debe encauzar las acciones sociales en razón de los siguientes factores: el factor ético y el derecho del hombre a gozar de un ambiente digno, el factor cultural de cada grupo humano, el factor económico y finalmente los límites físicos de cada región en particular, y del planeta en general.

Para decirlo con las palabras de Nuestra Propia Agenda (PNUD, 1990) «La paz con la Naturaleza, la armonización de las necesidades básicas de hoy con las del mañana, tales son pilares de un nuevo tipo de desarrollo, un desarrollo sostenible desde el punto de vista político, económico, filosófico y ético»; y este desarrollo sostenible deberá tener en 
cuenta al conjunto de población mundial. Debemos asumir que, de la misma manera que no puede suponerse que un mundo pobre - a pesar o gracias a su pobreza - ayude a conservar el ambiente para que otros obtengan una calidad de vida que a los primeros les está negada, pues carecen de lo mínimo indispensable, tampoco es posible pensar que en el seno de un mismo país, se acceda a crear condiciones adecuadas de vida que no sean accesibles al conjunto social. No es tampoco ético aceptar que los estilos de vida de nuestra generación puedan ser causa de problemas ambientales que afectan la dignidad de vida de las generaciones futuras.

La defensa del ambiente, la disminución de la pobreza y la extensión de los efectos positivos del desarrollo al con junto de la humanidad y a las futuras generaciones son parte de un mismo objetivo común. En última instancia, este planteo significa la paulatina contención en la confrontación de intereses nacionales y la búsqueda solidaria de propuestas y acciones compartidas.

Ahora bien, nuestros planteamientos iniciales nos llevan a definir que la política ambiental que promovamos deberá incluir la reparacíón de efectos perniciosos, la prevención de sus causas y, fundamentalmente, la creación de nuevos modelos de apropiación de recursos del ambiente.

Dichos modelos deberán tener en cuenta que a una visión reduccionista y unilineal del mundo, debe presentársele la opción de una visión que contemple la diversidad como punto de partida. Y ello exige reconocer las particularidades ambientales de cada región, como así también la realidad económica y social que le son propias.

«La naturaleza para ser dominada, debe ser obedecida» (Sir Francis Bacon). De la misma manera, podemos decir que para ser obedecida debe ser estudiada y conocida. Y es de la acción dirigida al conocimiento de la cual saldrán los modelos alternativos que permitan un desarrollo ecológicamente sustentable y socialmente accesible. 
El proyecto es, sin lugar a dudas, ambicioso, pero posible. Consiste en resolver de manera adecuada los conflictos existentes, buscando que la interdependencia que rige al conjunto de las naciones, se enriquezca con las particularidades que le son propias tanto a cada una de ellas, como a las subunidades que la componen. 


\section{INTRODUCCION A LOS RECURSOS Y RASGOS NATURALES DE LA PROVINCIA DE BUENOS AIRES}

\section{Mario E. Teruggi}

La mente que construye para siempre se apoya en el sólido suelo de la naturaleza, dijo el poeta. Esta sencilla verdad - lema de la renombrada revista científica Nature - suele desconocerse $\mathrm{u}$ olvidarse por quienes, en distintas capacidades y funciones, se ocupan de cuestiones ambientales o, si se prefiere, ecológicas. Cada uno - el político, el administrador, el arquitecto, el planificador, el ingeniero, el dirigente y el ciudadano común - tiene su propia idea de lo que es la ecología, que casi siempre se limita a instrumentar la defensa del medio ambiente de las amenazas humanas. Este enfoque implica una doble simplificación: por un lado pasa por alto las fuerzas y movimientos naturales que actúan en todo tiempo, y por el otro supone con infundado orgullo que el rey de la creación es el único ser capaz de atacar y eventualmente perturbar, modificar o destruir los equilibrios inestables existentes entre tierra, agua, aire y biontes, desde el virus hasta el hombre.

Si eliminamos mentalmente el hombre de la faz del planeta, la naturaleza seguirá su curso casi como si nada hubiera sucedido. Las inundaciones y las sequías proseguirán alternándose en el territorio bonaerense, los sistemas fluviales (Colorado, Negro, sistema del Plata) seguirán colmatando bahías o entarquinando estuarios, la competencia incesante de los seres vivos entre sí - ahora sin el hombre - se desarrollará libre de nuestras restricciones e imposiciones, y las especies herbáceas pampeanas asfixiarán los cultivos de la llanura.... La inmensa naturaleza proseguirá su marcha con un diminuto salto hacia atrás para colmar el espacio que el hombre ocupó.

Esta imagen inconcebible de la tierra deshumanizada nos permite visualizar que el hombre es parte de una naturaleza móvil, una especie de cinta rodante en la que hacemos nuestras 
piruetas sin afectar, creemos, la marcha de ella. Si tomamos la imagen oriental del tiempo, estamos de pie en la alfombra mirando hacia el horizonte de donde viene el movimiento: vemos pues el pasado y, a nuestras plantas, el presente; al futuro le damos siempre la espalda.

Cuando se habla de ecología metemos en acción el futuro, pues se trata de determinar qué va a pasar si aumentan o se acumulan los desechos humanos o si se modifica el estado natural con obras civiles. La única forma de evaluar que conocemos consiste en estudiar el universo o ecosistema que nos preocupa, mirando hacia atrás hasta el momento presente y, de allí, extrapolar hacia el avenir. Para muchas obras y acciones antrópicas, las previsiones se limitan a un siglo; para algunas, alcanzan cientos o aún miles de años, como en el ca so de los residuos radiactivos.

Para proteger el ambiente minimizando el posible daño humano se requiere pues conocerlo. Si seremos los médicos del planeta tierra - al que hemos ayudado a enfermar -, debemos conocer su anatomía y fisiología para juzgar cuales órganos han sido afectados por nuestras «intromisiones»y hasta qué grado. Debemos separar cuidadosamente lo que nosotros hacemos y lo que hace la naturaleza por su cuenta, y debemos ser capaces de medir - hasta donde sea previsible - los resultados de nuestras intervenciones. Sin estos recaudos, en lugar de medicina tendremos curandería.

Efectivamente, el fenómeno que se observa en torno al tema ecológico es en cierto modo comparable al que se producía en la baja Edad Media: por un lado, atraían la atención pública los alquimistas, magos, brujos y curanderos; por el otro, trabajaban inadvertidos los pocos que investigaban con seriedad. La ciencia parecía alineada con el primer grupo, no con el segundo. Modernamente, los que estudian el medio ambiente y tratan de evaluar sus condiciones y perspectivas no llaman la atención de nadie; en cambio, trasciende el clamor de las entidades y personas que denuncian los abusos concretos que se cometen contra el planeta. 
Los dos grupos, aunque guiados por principios distintos miran hacia un mismo objetivo que se suele denominar la preservación del planeta tierra. En realidad, no es el planeta en sí el que está en juego, sino nosotros mismos, de modo que el lema podría ser «preserve la especie humana». Lo paradójico de esta situación es que las amenazas de extinción no provienen de extraterrestres ni de fuerzas misteriosas - de esos que pueblan las fantasías de los escapistas de la ciencia, que siempre existieron - sino de nosotros mismos. El hombre lobo del hombre de la frase bíblica mantiene su vigencia, pero ahora, con los medios modernos, el canibalismo va acompañado de destrucción general, una asolamiento del planeta como nunca se ha visto. Y si el hombre no llegará nunca a destruir la vida sobre la tierra, hará mucho para dañarla, averiarla o disminuirla.

Es claro entonces que debemos saber cómo actuamos para poder controlarnos y en ese sentido se movilizan los grupos ambientalistas. Los grupos científicos están totalmente de acuerdo con esa posición, aunque entienden que debemos saber como actúa todo, lo biótico y lo abiótico, que se interpenetran en infinitas maneras. Limitar la investigación a lo humano implica meter una cuña entre el hombre y la naturaleza: al principio, el avance de la cuña apenas se nota porque su borde es un filo delgado pero a medida que progresa se amplía el espacio entre nosotros y el resto.

En efecto, el tema ecológico o ambiental es actualmente insoslayable y debe mencionárselo de cualquier modo que sea. En los últimos años, he tenido oportunidad de leer los llamados «informes ecológicos» de varios emprendimientos civiles, que reducen el ambiente a un manojo de datos vinculados al proyecto, sin ninguna investigación específica.

Para que no se repita la «escisión medieval», los grupos y proyectos ambientalistas deben estar muy atentos tanto a los atentados que comete la civilización como a la caracterización ecológica con su componentes, estructuras y fragilidades. Por desgracia, esta información básica 
suele estar incompleta o ser defectuosa, en cuyo caso el accionar protector se ejercerá con desconocimiento de qué se proteje y qué se perjudica.

En estos aspectos, la provincia de Buenos Aires ha sido pionera. En las décadas del cuarenta y cincuenta, cuando nadie hablaba de ecología ni se conocía el concepto como no fuera en el ámbito de la biología, se comisionó a eminentes naturalistas del Museo de La Plata para que confeccionaran los registros sistemáticos de la flora y la fauna bonaerenses, auque se omitió entonces el registro de los recursos minerales. Las obras publicadas en ese entonces son todavía básicas y de consulta ineludible, pero en los cincuenta años transcurridos se han producido muchos cambios y se han desarrollado nuevos estudios y enfoques de la realidad ambiental.

Gracias a estos registros se posibilita el acceso a una perspectiva «histórica» del ambiente, pues medio siglo es tiempo suficiente para detectar el sentido de las marchas, cambios e interacciones de los seres vivos y del medio físico. Sin ese referente histórico nuestra comprensión de los ecosistemas provinciales (llanural, litoral, fluvial, lacustre, palustre, deltaico o urbano) carecería de profundidad e imposibilitaría su proyección hacia el futuro. En consecuencia, la prevención y la previsión tropezarían con obstáculos insalvables que pueden originar políticas o programas contra producentes, aparentemente protectores y, a la larga, destructores.

\section{LLANURA Y SUELOS}

\section{Mario E. Teruggi y Alejandro Aragón}

El rasgo distintivo de las grandes llanuras herbáceas-llámeselas pradreras, estepas o pampas - es una horizontalidad carente de relieve que produce una sensación de monotonía en quien la visita o recorre. La frase del poeta para la pampa «piélago verde donde la vista se pierde sin tener donde posar», pretende reflejar la uniformidad desprovista de accidentes 


\section{DISTRIBUCION DE LOS PRINCIPALES PROCESOS DE DRAGRADACION DE SUELOS EN LA PROVINCIA DE BUENOS AIRES}

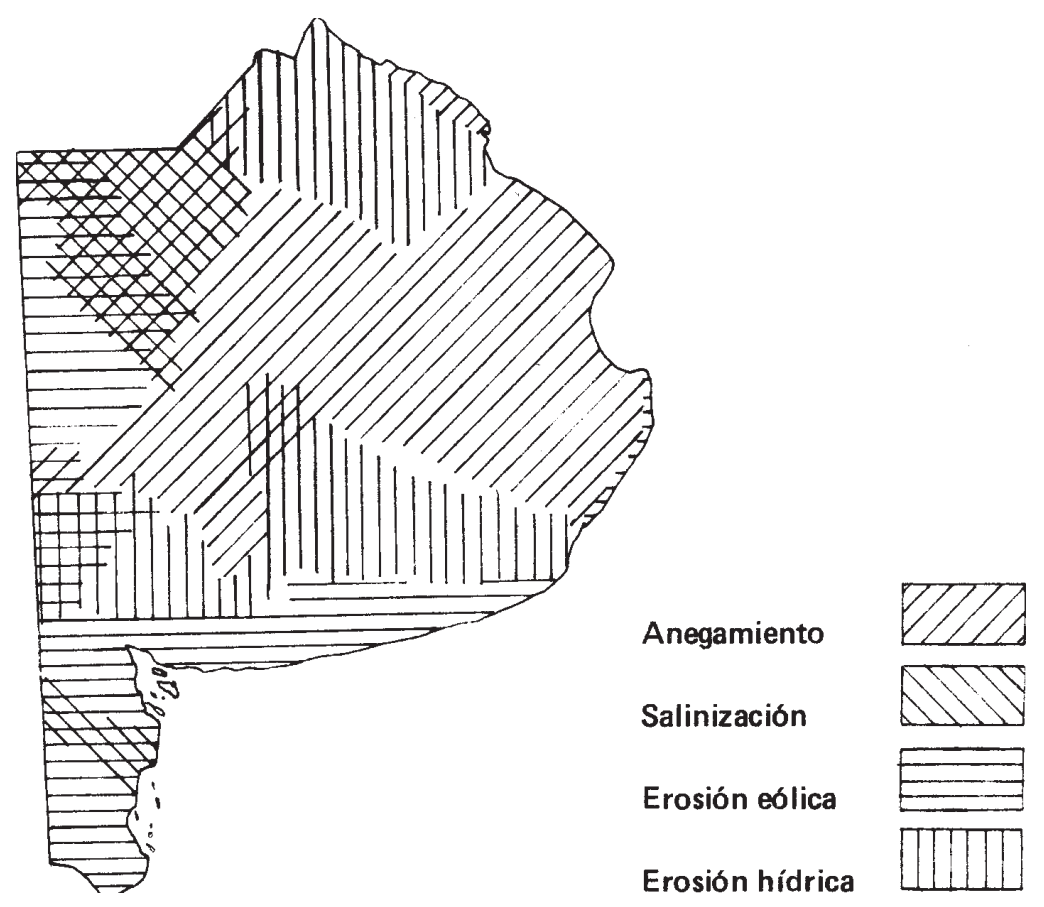

naturales, ni siquiera un árbol que interrumpa la línea del horizonte.

La uniformidad de un ecosistema es engañosa, pues no equivale a igualdad de todas partes. Es sólo una igualdad aparente, que es producto de una generalización basada en pocos puntos comunes: extensa superficie plana, vegetación de pastos y suelos más o menos oscuros (denominados chernozoides en otra época). Es bien sabido que a los occidentales los rostros chinos nos parecen todos idénticos pues generalizamos sus rasgos distintivos de color de piel, oblicuidad de ojos y oscuridad lacia de la cabellera. Esta «igualdad» facial desaparece cuando mantenemos tratos frecuentes con ellos pues distinguimos las características individuales por debajo de la uniformidad étnica.

La pampa vendría a ser nuestro chino ambiental, o, mejor aún, deberíamos escribir las pampas, dado que el concepto generalizado - ahora que la vamos conociendo más- se ha 
fragmentado y tenemos varias pampas dentro de la pampa. La miremos por donde la miremos - si es que la miramos, pues ese suele ser el gran problema-, se nos aparecen varios ecosistemas pampeanos. Así, dentro de la baja altitud promedio que ca racteriza la llanura, existe una gran porción de menor altitud, que desde hace varias décadas hemos dado en llamar «Pampa Deprimida», entidad con caracteres propios y problemática especial. Un ribete períferico litoral configura otra franja baja desde el delta hasta el río Colorado. El centro y el oeste de la provincia pasa a ser, en medida creciente hacia el poniente, la Pampa Psamítica, donde predominan los mantos arenosos (sand sheets) con sus médanos superficiales. Bordeando los sistemas montañosos de Tandilia y Ventania hay una Hipsopampa, una pampa algo elevada por los ascensos serranos, que constituye un ecosistema diferente. Y por todos lados, en paños grandes o en retazos, la pampa que no es ninguna de las anteriores, la Eupampa, que no es ni deprimida ni alzada ni arenosa ni salitrosa, y que es el prototipo o modelo que dio origen a la generalización de pampa.

Nos encontramos pues con por lo menos cinco tipos de pampas (no incluimos aquí la región al sur de Bahía Blanca, con rasgos patagonoides), cada una subdivisible en categorías menores. Estas cinco pampas se nos presentan cualquiera sea el enfoque que utilicemos. Si es el geológico, las distiguismos en base a geomorfología, sedimentología, estratigrafía e hidrogeología; si es el pedológico, por conjuntos de suelos diferenciables; si es el biológico, por floras y faunas reconocibles por especifidad o cantidad; si es el antropológico, por radicaciones ajustadas a las condiciones locales; si es el productivo, por los variados rindes, explotaciones y extracciones de distintos valores. Se podría seguir.

Las cinco pampas son ambientes naturales, con sus agentes, factores y parámetros propios. El hombre los ha heredado y actúa sobre ellos, pero no los ha creado. El dominio eólico del oeste bonaerense existe desde antes de que hubiese pobladores humanos, así como existía allí 
la erosión y depositación eólicas y la colmatación de las grandes voladuras por las aguas de las precipitaciones abundantes. El drenaje impedido o semiimpedido de la Pampa Deprimida no es de ahora, ni tampoco la erosión hídrica en la Hipsopampa o la pampa litoral.

Este es el patrimonio natural que hemos recibido y es nuestra responsabilidad preservarlo, vale decir, afectarlo en forma mínima con nuestras acciones, e incluso, con buenas bases de investigación, corregir hasta donde sea posible aquellos agentes ecológicos que actúan en desmedro de los ecosistemas.

Las cinco pampas, que se traslucen en la carta de procesos de degradación de suelos, son nuestros hábitat de bonaerenses. Su epidermis, el suelo, es la membrana que los cubre y posibilita los intercambios; cualquier escoriación amenaza convertirse primero en eczema y luego en úlcera. El patrimonio llanura está indisolublemente legado al de los suelos y su manejo.

Para estos fines, aparte de determinaciones específicas, se requiere la revisión de los antecedentes históricos del área del emprendimiento y de la zona que ella afecta.

Uno de los aspectos relevantes de la gestión de recursos naturales, es la atención de la conservación del suelo. La preservación de este componente de la biosfera representa para el hombre no sólo una forma de sostener la productividad, sino también una necesidad relativa a la calidad ambiental.

Un suelo es el resultado de largos y complejos cambios que modelan este cuerpo tridimensional con proporciones particulares de sólido, líquido y gas, cuya evolución y funcionalidad dependen del material originario, el clima, el tiempo, y la biota. Como los organismos vivos nace madura y envejece, puede incluso enfermar y morir, naturalmente o en forma inducida por el hombre. En él ocurren procesos esenciales para la vida, no sólo de las plantas vasculares sino del planeta. Es un filtro selectivo que recicla y también produce sustancias críticas para el 
ecosistema, siendo por lo tanto utilizado, directa o indirectamente por todas las formas de vida.

El interés de la especie humana por el dominio de su entorno y en particular por el suelo, se remonta a la agricultura neolítica. A través de un largo camino se llega desde el empirismo milenario, a desarrollar conocimientos científicos que fructifican en avances notables de la agrotecnología. Los fertilizantes herbicidas y plaguicidas sintéticos, junto a la genética han posibilitado alcanzar producciones imposibles de soñar hace no más de un siglo. Paradojicamente, los viejos procesos de degradación continúan ocurriendo y aún aparecen algunos nuevos atribuibles a la panacea sintética.

Debe partirse de la base de que toda técnica de producción conocida tiene limitaciones y contraindicaciones, incluidas las llamadas conservacionistas. Esto no es tenido en cuenta generalmente, prefiriéndose recurrir a acciones correctivas y casi nunca a las preventivas, aún cuando estas últimas suelan ser más simples y eficientes. Hasta los países más conservacionistas, sólo han adoptado políticas serias de control después de haber sufrido consecuencias graves del deterioro.

Ocurre que el suelo es considerado un recurso renovable, con capacidad de regeneración a través de procesos de edafización bastante bien conocidos. Sin embargo, se está lejos de haber desarrollado tecnologías de costo razonable que posibiliten la reconstrucción de un suelo productivo en poco tiempo. Por otra parte se dispone de todo un paquete técnico con multiples opciones, para producir reduciendo al mínimo los riesgos de degradación.

En este sentido, la formulación de la tecnología específica para un tiempo y lugar determinado está subordinada a decisiones previas sobre qué, por qué, y para qué producir. Estos interrogantes deben dilucidarse en un análisis de costo - beneficio que contemple aspectos culturales, sociales, am bientales, y ciertamente económicos. Con mayor frecuencia de lo que se supone los sistemas actuales de producción no responden racional e integralmente a este 
conjunto de intereses, pudiendo ejemplificarse tanto en las propuestas más tecnificadas como la «revolución verde», como en otras más groseras como la de extracción a tierra arrasada en delicados ecosistemas, en todos ellos la degradación del suelo refleja más o menos rapidamente en el deterioro de la calidad de vida de los supuestos beneficiarios.

Existe un convicción ancestral sobre la feracidad del territorio bonaerense. Sin embargo, la presión creciente de uso de la tierra principalmente como consecuencia del proceso de agriculturización en el último lustro, a puesto de manifiesto la irracionalidad de algunos de nuestros sistemas agroproductivos.

La erosión hídrica se manifiesta, en formas moderadas o severas, en cinco millones de hectáreas de la provincia ubicadas en el ámbito mejor dotado del país. Se pierden así unas diez toneladas/Ha.año de los mejores suelos, existiendo al presente unas cien mil hectáreas que por la gravedad de su estado resultan difícilmente recuperables. La pérdida de productividad en este caso es enmascarada en parte por la tecnología de cultivo y mayormente por la sustitución de cultivos tradicionales, como el maíz, por la soja que muestra una mayor adaptación a suelos degradados pero a la vez expone más la superficie a los agentes responsables de la erosión, o sea la lluvia y el escurrimiento.

La erosión eólica sólo ha reducido su expresión en favor de una mayor pluviosidad en los últimos decenios, lo que a su vez posibilitó la expansión de la actividad agrícola hacia el oeste. Recordemos que algo similar ocurrió en Norteamérica en la primera mitad del siglo y que las consecuencias fueron catastróficas.

La erosión eólica afecta actualmente a unos cuatro millones de hectáreas de la provincia, lo que significa algo más del doce porciento de su superficie. Las condiciones climaticas favorables para la detención de su avance, han generado al mismo tiempo inundaciones, erosión hídrica y procesos de salinización no menos preocupantes. 
El problema de las inundaciones merece una mención aparte. La teledetección vía satélite ha permitido su estudio con una nueva perspectiva, no obstante estamos lejos de poder ofrecer soluciones integrales. La Pampa Deprimida tuvo en el año 1980 tres millones de hectáreas ocupadas por agua durante cinco meses y a esto debemos sumar unos dos millones y medio de hectáreas inundables en el oeste donde, además, se suscitan graves problemas de salinización.

El hombre tiene distintos grados de responsabilidad en la ocurrencia de estos procesos de degradación, pero es inequívoca su obligación de controlarlos por una cuestión esencialmente práctica. De hecho somos dependientes de la naturaleza tal cual es, ella en cambio puede adecuarse a la ausencia del hombre como ya lo ha hecho con otras especies.

Debemos ser sumamente cuidadosos en la afectación de nuestros recursos, más allá de la urgencia de generar divisas mediante productos devaluados por un mercado de subsidios.

Debemos hacer un gran esfuerzo de imaginación para generar propuestas técnicas y científicas que garanticen alta productividad sin degradación del medio.

Debemos, en definitiva, asumir nuestro compromiso con la propia calidad de vida y la de futuras generaciones. Contamos para ello con lo más importante: los recursos humanos calificados para protagonizar este desafío. El acierto de las decisiones y acciones que emprendamos definirá si es que estamos avanzando o retrocediendo.

El mapa adjunto representa, esquematicamente, la extensión y ubicación de las zonas de riesgo degradativo en sus principales formas, actual o potencialmente presentes en la provincia de Buenos Aires. Nótese la existencia de áreas con superposición de riesgos y que, en alguna medida, todo el te rritorio es suceptible de sufrir procesos de deterioro edáfico. 


\section{AGUA Y MEDIO AMBIENTE}

\section{José M. Sala}

El hombre es él y el medio ambiente, el que está conformado por «recursos naturales integrados» entre los cuales los recursos hídricos cumplen un papel de vital importancia.

El ciclo hidrológico tiene, con sus cambios espacio-tem porales, una marcada acción en el ambiente. Pero además incide en la distribución, el tipo y los cambios de los seres vivos. La actividad humana, por su parte transforma el medio con miras a obtener un mayor bienestar ocasionando, aún en los países desarrollados, efectos perniciosos para el hombre.

Es evidente que para usufructuar plenamente del medio ambiente, disminuyendo al mínimo los riesgos, la humanidad deberá acrecentar el conocimiento científico de sus recursos naturales, incluyendo el de los recursos hídricos.

Las soluciones simplistas a los problemas que plantea el medio ambiente, son inoperantes y producen efectos secundarios perniciosos, los cuales pueden ser visualizados cuando se evalúa la naturaleza con rigurosidad científica.

En este sentido, la evaluación del ciclo hidrológico fue complementada con el conocimiento de las aguas subterráneas a partir de fines del siglo XIX. Dicha complementación se acentúa con la incorporación de la definición de la hidrología y sus divisiones efectuada en la reunión Executive Committee of the International Association of Scientifíc Hydrology (Zurich, 1938).

Sin embargo, es a partir de los trabajos de Toth (1962) cuando se acentúa la necesidad de considerar las aguas superficiales y subterráneas en forma conjunta, al efectuar investigaciones relacionadas con el ambiente.

Con relación a la Provincia de Buenos Aires, tanto los relatos históricos como los de divulgación científica, informan que los grandes problemas ambientales extremos son las 
sequías y las inundaciones. En 1884, Florentino Ameghino plantea un hito importante al señalar que, en contra de la solución simplista de evacuar los supuestos excesos hídricos, los períodos húmedos y los períodos secos deben ser analizados y considerados en forma conjunta. No obstante, la sociedad preocupada por las catástrofes naturales que la afectaban, persistió en la búsqueda y en la ejecución de soluciones sin fundamento técnico, las cuales no le permitieron solucionar ni atenuar los problemas de las inundaciones y de las sequías y por el contrario han agravado más aún las mismas.

En el año 1956 se produce otro hito con la Conferencia sobre desagüe de la Provincia de Buenos Aires, realizada en la Facultad de Ingeniería de la Universidad Nacional de La Plata, en la cual, los expertos llegaron entre otras a las siguientes conclusiones:

«No aconsejar la adopción de ninguno de los planes propuestos hasta el presente, por cuanto están fundados en una insuficiente documentación técnica; el proyecto de obra aprobado en 1974 por el Poder Ejecutivo de la Provincia debe reverse por no estar exento de la deficiencia advertida».

«No circunscribir el Plan futuro de obras a la llamada zona inundable; deberá tener en cuenta, en su concepción integral, los problemas que se plantean en todas las regiones de la Provincia».

«Organizar, con carácter científico, que es ajeno a todo criterio personal, los estudios especializados, atendiendo al aprovechamiento integral del agua...».

Ambas propuestas, la efectuada por Florentino Ameghino en 1884 y la realizada en la Conferencia sobre Dasagües en 1956, hacen referencia a las aguas superficiales y las subterráneas. Sin embargo, estas últimas fueron consideradas con las limitaciones propias de los conocimientos hidrológicos de la época en las que se efectuaron.

En el año 1987 Bravard dió a conocer los primeros traba-jos efectuados sobre la situación de las aguas subterráneas en la Provincia de Buenos Aires. A posteriori, otros autores efectuaron 
múltiples y relevantes trabajos, respondiendo a inquietudes personales. Los mismos no tuvieron continuidad y muchas veces fueron realizados sin tener en cuenta la evolución de los conocimientos científicos.

Como consecuencia de la reunión de 1956, se creó el Departamento de Hidrología dependiente de la Dirección de Hidráulica de la Provincia de Buenos Aires, el que tenía como objetivo investigar tanto las aguas subterráneas como las superficiales. A partir de ese momento, como consecuencia de dicha creación, se iniciaron mediciones de aforos en los ríos e investigaciones regionales de las aguas subterráneas. En el primer aspecto considerado las mediciones se efectuaron sobre caudales fluviales y precipitaciones. En el segundo aspecto los estudios fueron sistemáticos y efectuados con la participación del Ministerio de Obras Públicas de la Provincia, el Consejo Federal de Inversiones, la Facultad de Ciencias Naturales de la Universidad Nacional de La Plata, y contaron con el aporte de expertos internacionales invitados por la Comisión de Investigaciones Científicas de la Provincia. Sin embargo, por motivos de diversa índole, los trabajos tampoco tuvieron continuidad.

De esta manera, si bien los conocimientos generales acumulados son importantes, la falta de sistematicidad y continuidad de las investigaciones hacen que los mismos sean insuficientes para responder a la demanda de soluciones que reclama la sociedad.

La posición geográfica de la Provincia de Buenos Aires, su extensión, su carácter de llanura de pendiente topográfica extremadamente baja $\left(0.1\right.$ por $\left.10^{-3}\right)$, su extensa costa marítima, su dilatada plataforma submarina, y su geología y geomorfología dan origen, en razón del clima imperante, a un síndrome hidrológico integrado por un mosaico de particularidades.

Esta situación se encuentra agravada por el anárquico desarrollo demográfico efectuado sin conocimiento de los hechos naturales.

Las características descriptas, permiten comprender las razones por las cuales, a pesar de 
que se cumplan las leyes generales del ciclo hidrológico, los procesos de infiltración y la capacidad de almacenamiento subterráneo adquieren un peso relativo mayor que el escurrimiento y almacenamiento superficial.

Ahora bien, en relación a los recursos hídricos, las catástrofes fundamentales que tienen lugar en el territorio de la provincia, son los excesos de agua y las sequías; ambas catástrofes agravadas, claro está por la acción humana. Sin embargo, debe tenerse presente que cuando se considera el nivel regional los excesos de agua son, generalmente, aparentes.

Además, y en razón de las condiciones naturales imperantes, las aguas suelen tener alta contaminación química sin la participación del hombre.

Las catástrofes naturales no pueden evitarse. El hombre puede atenuar sus efectos en la medida en que sepa adaptarse a la naturaleza sin contribuir a acrecentar sus problemas. Puede también prevenirlas. Los grandes cambios climáticos, que dan origen a los fenómeno catastróficos señalados, han dejado sus rastros impresos en las características geológicas y geomorfológicas, habiendo sido interpretados y descriptos por distintos autores.

En relación a los aspectos históricos debe recordarse que el Río Salado fue navegable hasta la Laguna de Chascomús; la Laguna del Monte ( Pdo. de Guaminí ) fue ictícolamente productiva, como así también lo fueron otros cuerpos lénticos del noroeste de la provincia, y que hasta hace pocos años eran frecuentes las tormentas de polvo producidas por la voladura de los suelos desechados. Un ejemplo de lo que decimos esta dado por la perdida económica producida por la construcción de la planta de tratamientos de aguas cloacales en Pehuajó, la que al haber sido ubicada en el lecho ocasionalmente seco de la laguna, se haya hoy inutilizada dado que la laguna volvió a cumplir sus funciones como tal.

Por otra parte, son numerosos los datos que confirman la facilidad de infiltración, la que 
aparece como una variable relevante del ciclo hidrológico de la Provincia de Buenos Aires. Este hecho, detectable a simple vista cuando se controlan jardines sometidos a riegos o cuando se acumula el agua de lluvia en zonas no drenables, puede ser demostrado a través de datos científicos. Entre los datos científicos debemos considerar, la presencia natural de nitratos en la napa freática, la existencia, en zonas donde el balance hídrico es deficitario en lentes de agua dulces suspendidas en aguas saladas continentales, la variación de los niveles freáticos en relación a las precipitaciones, y los balances hidrológicos.

En otro orden de cosas, la mencionada Conferencia sobre Desagües en la Provincia de Buenos Aires, se expidió sobre los canales trazados con anterioridad a 1956. A pesar de ello, sin mayores estudios ambientales y menos aún hidrológico, aplicando indebidamente el principio de retención de las aguas establecido por Ameghino, se construyó en la década del 60, el canal que lleva lamentablemente el nombre del científico. A ésta obra se le asigna en la actualidad y en forma desaprensiva el origen de las inundaciones de las lagunas del centro oeste, sin que se hayan evaluado sistemáticamente y durante un tiempo significativo, los caudales del canal en cuestión. De hecho, hemos olvidado que a principio de siglo se produjeron inundaciones de igual o mayor gravedad que las actuales, cuyos efectos eran aún observables en el verano de 1928-29. A causa de dichas inundaciones se efectuarón millonarias demandas contra el Estado.

En razón de las condiciones ambientales de la Provincia de Buenos Aires, el hombre ha utilizado y utiliza intensamente las aguas subterráneas. Dicha utilización fue efectuada inicialmente, de manera racional, utilizando el agua proveniente de aljibe para uso del hombre y las aguas salobres o saladas como complemento.

Posteriormente, al aumentar las necesidades de agua fueron introducidas metodologías de explotación inadecuadas las que estaban, supuestamente fundamentadas por conocimientos 
científicos alcanzados en los países más desarrollados. De esta manera se relegaron las enseñanzas de Wichman quien a principio de siglo adoptó, para la zona de Puerto Deseado, una distribución areal de los pozos y redujo el caudal unitario de cada uno de ellos evitando, de esta manera, depresiones exageradas, agotamiento y salinización. Es común hallar ejemplos de abandono prematuro de pozos (La Plata y Mar del Plata) cuando no se cumplió con la metodología propuesta.

La ciudad de La Plata es uno de los ejemplos típicos de derroche del recurso hídrico. En efecto, la sobreexplotación de los pozos para la obtención del agua potable produjó la invasión de las aguas saladas naturales, el agotamiento de la capa freática, y la subutilización, sin estudios previos de la capacidad de almacenamientos subterráneos, además de permitir que los nitratos emigren hacia el acuífero Puelche. Otros ejemplos pueden obtenerse de localidades del interior de la Provincia (Gral. Villegas), en las cuales la sobreexplotación de «lentes» de aguas dulces produjó acumulación de sales en el agua potable.

Pero además, los grandes conos de depresión producidos por la sobreexplotación de los acuíferos, como los que ocurren en Buenos Aires o Mar del Plata, han alterado la relación entre aguas superficiales y subterráneas. De tal manera, se invirtió la relación entre ellos, pasando los efluentes a influentes.

Por otra parte, los desechos domiciliarios e industriales impactan en el medio ambiente, produciendo contaminación de los recursos hídricos, tal como puede observarse en los aledaños de la ciudad de La Plata y en las consecuencias para el Río de la Plata el que fué utilizado en razón de la supuesta capacidad de diluir y disipar la totalidad de los efluentes que se le derivó. De hecho la vida acuática ha desaparecido del puerto de la ciudad de La Plata.

Finalmente, debe considerarse el uso indebido e indiscriminado de fertilizantes y agroquímicos no biodegradables los que son transportados y concentrados en los cuerpos de 
aguas superficiales y, por infiltración, transportados a las agus subterráneas que al ser sobreexplotadas, aceleran la concentración de los contaminantes. De la misma manera los contaminantes atmoféricos son «arrastrados» por el agua de las lluvias siendo incorporados a las aguas superficiales y por lo tanto a las subterráneas.

\section{GEOLOG IA EXTRACTIVA}

\section{Isidoro B. Schalamuk}

Entre las actividades industriales que afectan al «medio ambiente natural», la minería es una de las más notables, teniendo en partes peculiaridades propias que la diferencian del resto de las industrias. Se trata de una actividad básica dedicada a la obtención de georecursos para el abastecimiento de la población. La sociedad reconoce una fuerte dependencia de los recursos minerales y sus productos derivados, con el desarrollo de la humanidad y la influencia sobre su calidad de vida.

Como contrapartida, la minería afecta al medio en casi todas sus manifestaciones, debido a que esa industria, dedicada a la extracción y transformación primaria de materiales de la corteza terrestre, genera condiciones que llevan a la ruptura del equilibrio de los procesos naturales que actúan en su entorno. La importancia de ese impacto varía de acuerdo al tipo de 
mineral o roca que se explota, las características de los yacimientos, ubicación geográfica, conformación geológica y modalidad de explotación.

El aumento de la población mundial, las necesidades de los países en vías de desarrollo y la creciente demanda de los países industrializados comportan una rápida aceleración de las tasas de consumo de materias primas minerales. Actualmente se estima que ese consumo, considerado en su conjunto, se duplica cada 20 o 25 años.

La confrontación de estos dos hechos -un recurso cuyas existencias son limitadas y un consumo en crecimiento casi explosivo- plantea un problema de importancia decisiva para el futuro de nuestra civilización.

Los especialistas consideran que, a mediano plazo, los recursos minerales serán suficientes si son investigados y evaluados entensamente, si son reciclados al máximo determinados materiales y si se desarrollan productos de sustitución. Para dar sólo un ejemplo, podemos señalar que en los países más desarrollados (Japón, Estados Unidos, Alemania) el consumo anual per cápita de minerales no energíticos superan las 8 toneladas. Nuestro país, en los años setenta, alcanzó su maximo con un consumo del orden de las 2 toneladas por habitante.

Los nuevos enfoques tienen presente la limitación de los recursos naturales y la fragilidad de los ecosistemas, suscitándose entre los economistas, naturalistas y políticos encendidas polémicas y no poca confusión. No obstante, la conciencia que se va adquiriendo acerca de la limitación de los recursos, obliga a que se ejercite nuestra capacidad para solucionar la demanda futura de materias primas (programando una racional explotación y transformación) en claro equilibrio con la conservación de la naturaleza, para salvaguardar el patrimonio que representa el medio y los recursos naturales a legarles a las generaciones futuras.

El hombre de hoy está aprendiendo a valorizar la naturaleza en toda su magnitud, no sólo 
como fuente de recursos que le permiten vivir. La conservación de los recursos naturales pasa a ser ante todo un principio básico en sí, y casi nadie puede aceptar concientemente la desaparición de alguno de sus elementos. De esta forma el hombre se enfrenta al imperativo de considerar el problema del medio ambiente y por consiguiente el de su conservación, buscando soluciones técnicas, jurídicas y culturales posibles para alcanzar un desarrollo sostenible, que le permita conservar el equilibrio de ese medio ambiente natural del cual él es parte integrante.

Por consiguiente, si nuestro propósito es lograr un aprovechamiento racional de los recursos naturales, el conocimiento de la geología es fundamental. Significa ello que el conocimiento debe ser completo y no fragmentario, con el recurso de distintas disciplinas que permitan la gestión del sector minero, con una visión racional e integradora.

El Banco Mundial y otros organismos multilaterales que tienen experiencia en la evaluación de impactos en proyectos de diferente índole, sonstienen que los costos relacionados con la protección ambiental y la salvaguarda de la salud y el patrimonio cultural inciden en los proyectos mineros en porcentajes inferiores al 3\% del total de la inversión. Se puede señalar entonces, que es factible obtener soluciones sencillas y económicas tendientes a eliminar, corregir o atenuar los problemas ambientales siempre que se efectúen los estudios y evaluación del impacto, antes de instrumentar definitivamente los proyectos.

La evaluaciones de impacto tienen por fin prevenir y pueden efectuarse parcial o integramente, esto es contemplando el impacto global o sólo impactos parciales. En el caso de los proyectos mineros es recomendable una evaluación geobiofísica y sociocultural, considerando todo el ecosistema.

En todos los casos, los costos insumidos en la protección y control del ambiente se distribuyen entre la sociedad y la industria. A medida que se apliquen regímenes de control, disminuyen los costos sociales y aumentan los industriales. 
Si la industria no invierte en controles, la sociedad debe gastar cada vez más en reparar el daño producido, y muchas veces esos perjuicios son irreparables.

Dado el volumen de los minerales no metalíferos y rocas de aplicación que se extraen del subsuelo bonaerense, la provincia marcha a la vanguardia de la minería nacional. Su territorio aporta a la industria extractiva del país, participando en tal sentido con un $40 \%$ en el rubro rocas de aplicación y en un casi 30\% minerales no metalíferos al producido nacional.

La actividad minera que se despliega en el ámbito provincial se debe a las significativas reservas geológicas que encierra, a la calidad de los materiales y a la excelente ubicación de los yacimientos respecto de los principales centros urbanos y de sus industrias, que se distribuyen esencialmente en el sector litoral y en el Gran Buenos Aires.

La seguridad de mercado que tienen los recursos mineros de esta provincia, ha originado que capitales privados decidieran correr los riesgos de la actividad e hicieron de la minería bonaerense una de las más importantes a nivel país.

Los diferentes centros de producción se localizan principalmente en los dos grandes elementos morfoestructurales positivos, de diferente edad y constitución geológica, eso es, Sierras Septentrionales y Sierras Australes, y también en su dilatada llanura que cubre más del 95\% del área provincial.

En las Sierras de Tandilia o Septentrionales se desarrolla la mayor actividad extractiva de la provincia y del país, aprovechándose sus diferentes elementos constituyentes. Las citadas sierras incluyen las áreas de Sierras Bayas, lugar de gran movilización de caliza, dolomita y rocas graníticas; Tandil que se caracteriza por el aporte de material pétreo de composición granítica; Balcarce-Chapadmalal-Mar del Plata con producción de cuarcita y arcillas; y Barker-Claraz-LópezSan Manuel-Chillar con el abastecimiento de caliza y arcillas plásticas y refractarias.

La contribución de las sierras Australes o de Ventania a la producción es sensiblemente 
más reducida respecto de la unidad antes citada, con explotación de rocas graníticas y cuarcitas.

Importante es el aporte de la Llanura Bonaerense, segundo elemento morfológico, en el rubro de minerales no metalíferos con el aprovechamiento de evaporitas, destacándose el yeso que es extraído de las cuencas del río Quequen y arroyo Pescado Castigado (partido de Necochea) y la sal común y sulfato de sodio que provienen de los mumerosos cuerpos salinos existentes en la porción sudoeste de la provincia y en zonas limítrofes con La Pampa.

Es significativo el aprovechamiento de los bancos de tosca ampliamente distribuidos en los partidos del sudoeste de la provincia y también en los de Pilar y La Matanza. Asimismo, son destacables los volúmenes de producción que alcanzan los materiales calcáreos pertenecientes a los conglomerados y cordones conchiles que se extienden en una faja subparalela a la costa, desde las proximidades de la ciudad de La Plata hasta las cercanías de Mar del Plata, con centros de producción muy activos en las adyacencias de las poblaciones de Magdalena, Pipinas, Cerro de la Gloria y Castelli.

Las principales áreas de extracción de arenas y gravas se ubican en el río Paraná, paraná Guazú e islas del Delta, así como en el litoral marino donde se extraen a partir de las acumulaciones de playa, dunas y médanos.

Esta breve síntesis acerca de la producción mineral en la provincia da una idea de la actividad extractiva y del impacto en sus diversas manifestaciones: alteración del paisaje (la ciudad de Tandil es una de las más afectadas); destrucción parcial y aún total de la vegetación y capa superior del suelo (explotación de yeso, conchilla, arcilla, etc.); propagación de ruidos (por uso de explosivos); emisión de polvo, gases de combustión y productos derivados de la calcinación, que origenan problemas a las poblaciones próximas a los complejos mineros; graves consecuencias de la explotación indiscriminada de arenas y gravas en los lechos de los ríos y costas del litoral atlántico, son sólo algunos de los ejemplos. 
Con la certeza de que la producción minera es una importante actividad para nuestro desarrollo, lejos de desprotegerla, la meta debe ser adecuarla e impulsar a que se pueda obtener la máxima utilidad de los recursos no renovables, incorporando normas para la evaluación del impacto ambiental y el estricto control para evitar la agresión, o imponer métodos y prácticas para disminuir los riesgos de alteración del equilibrio ecológico.

Debe tenerse presente que si bien la industria extractiva suele crear una serie de alteraciones físicas y sociales, que por lo general poseen carácter negativo, al mismo tiempo contiene aspectos positivos para el entorno socioeconómico en cuanto genera trabajo, bienestar y recursos pecuniarios al hombre que participa de ella.

Las cartas ambientales y cartas de ofertas del medio son herramientas de suma utilidad para el diagnóstico y la toma de decisiones, en lo relativo a planificación y ordenamiento ambiental.

Además de incrementar el conocimiento del ecosistema, este tipo de cartografía permite orientar y establecer pautas para el mejoramiento de la calidad de vida y el desarrollo armónico de las potencialidades de un área determinada. Por otro lado, cuando contempla la tendencia evolutiva de los componen tes ambientales, puede predecir posibles efectos positivos o negativos y ofrecer alternativas favorables a esa naturaleza y a la sociedad en particular para aprovechar los recursos de la tierra, racional equilibrada y justamente. El conocimiento de la realidad ecológica del medio se dirige precisamente a este objetivo, orientando la actividad minera en la dirección que la cartografía temática básica lo sugiere.

Los estudios multi e interdisciplinarios si se efectúan a su debido tiempo, encuentran normalmente soluciones sencillas y económicas para eliminar y reducir los efectos del deterioro ambiental que origina la industria extractiva. Se estima impostergable incorporar al Código de Minería disposiciones y reglamentos específicos que permitan obtener la mayor utilidad de 
los recursos mineros, pero sin destruir o afectar el equilibrio ecológico, estabeciendo las condiciones mínimas de operabilidad de las explotaciones y la obligatoriedad de la ejecución de evaluaciones de impacto ambiental.

El tema en su conjunto y la política a seguir, deben ser considerados por los que tienen la responsabilidad de legislar, por los empresarios, economistas, planificadores, científicos y profesionales relacionados con el quehacer minero y todos aquellos preocupados por el medio ambiente y la calidad de vida.

\section{FLORA, VEGETACION Y ECOSISTEMA}

\section{Jorge L. Frangi}

La provincia de Buenos Aires constituye un espacio cubierto por una mezcla de vegetación característica de pastizales templados en una topografía mas o menos llana a suavemente ondulada, y vegetación arbustiva por el sur y arborea por el oeste y noreste. Los ejes serranos de Ventania y Tandilia son enclaves importantes para la flora de diverso origen y laboratorios evolutivos de flora y fauna. Los sistemas de médanos, los ambientes salinos y lagunares, por otra parte, aparecen habitados por especies adaptadas a suelos sueltos y permeables, anegadizos o de alta salinidad.

La vegetación es parte de los sistemas de la naturaleza o ecosistemas; éstos últimos integrados por plantas, animales y microorganismos interactuando con la materia inerte y la energía. La vegetación, en especial en los sistemas terrestres, es el rasgo que caracteriza el aspecto de los sistemas ecológicos, que muchas veces sirve para establecer sus límites y que funcionalmente representa la vía de transformación de la energía solar en energía potencial de la materia orgánica a través de la fotosíntesis para el sostenimiento de la vida en el ecosistema. 
La fisonomía actual y la composición florística de la vegetación, como también la fauna, son el resultado no sólo de fenómenos evolutivos bajo una geología y clima que han variado a través del tiempo, sino de los eventos que en tiempos históricos se asocian a la presencia humana en la zona. La abundancia y distribución de árboles poco tiene que ver con el paisaje bonaerense prehispánico. La flora nativa es confundida por el lego con numerosas especies introducidas beneficiosas o perjudiciales - que para muchos parecen haber estado desde siempre en la Pampa bonaerense. La agricultura y la ganadería y otras formas de uso de los ambientes rurales, han sumado a la transformación de la cobertura vegetal una nueva geometría del paisaje. La extracción de materiales de construcción (rocas de aplicación en las sierras, suelo para ladrillos, arenas en la costa, conchillas en el litoral) junto a la instalación de centros urbanos y de disposición de residuos, obras de ingeniería no muy felices desde el punto de vista ecológico, y contradictorias o imcompletas decisiones de orden político o administrativo, han generado tierras disturbadas o destruidas, nuevos ambientes en algunos aspectos útiles y en otros conflictivos en el corto o mediano plazo, fenómenos de contaminación ambiental, equivocos en el destino de tierras no aptas para el desarrollo de planes de viviendas populares, pérdida de excelentes recursos naturales de lenta renovación como el suelo, etc.

Ha cambiado la diversidad biológica bonaerense? Se están perdiendo especies? Advertimos que perder especies y ecosistemas es perder bienes y servicios? Consideramos a la naturaleza como un patrimonio? Disponemos de un relevamiento actualizado de las especies y sus potencialidades de diversa indole? Advertimos que existe una percepción cambiante del valor de los recursos? Que muchas veces hablamos de conservación de la naturaleza y el medio que no son otra cosa que el entorno humano - y de qué dependen esos sujetos de conservación y protección? O peor aún, que no tenemos un conocimiento cabal de muchos sitios que suponemos estamos conservando?

Advertimos que sin conocimiento no hay oportunidades? Que la tecnología no es perfecta? 
Tenemos conciencia que estamos reemplazando sistemas enteros y conocemos casi nada de su funcionamiento? Nos damos cuenta que en el afán de resolver cuestiones mas o menos urgentes bajo premisas económicas comprometimos la calidad de vida de nuevas generaciones? Consideramos nuestros prejuicios en el análisis y calificación de los organismos y sistemas que habitan el territorio provincial? Nos damos cuenta de que manera se encuentran interrelacionados los sistemas terrestres con los acuáticos y como nuestras actividades cotidianas y nuestras obras inciden sobre ellos y sobre nuestra propia población? Prestamos atención a los recursos vegetales que no forman parte de una economía de escala pero que son fundamentales para lugareños? Entendernos que la protección del medio ambiente no es un problema de conservar a otros organismos sino de hacerlo con nuestro propio soporte vital? Que los criterios y actitudes conservacionistas no son por lo tanto para ser aplicados a áreas protegidas si no a todo el territorio provincial? Que la calidad de vida no se define solamente con bienestar económico y áreas de producción sino también con áreas naturales? Conmensuramos exactamente cúal es el papel que la educación general y sus responsables tienen en la formación de ciudadanos conocedores de sus respondabilidades personales y sociales que sin duda incluyen al medio ambiente?

Nuestra estrategia de uso de la tierra manifiesta un sinnúmero de conflictos ambientales: ignorancia o falta de conceptos claros vinculados al tema por distintos actores, demandas incompatibles con las posibilidades de los ecosistemas terrestres y lagunares, falsas o engañosas concepciones del progreso y desarrollo que se traducen en el uso indebido de las tierras, comportamientos dirigidos exactamente en la dirección opuesta de los que se verifican en sistemas naturales que han persistido por milenios.

Es hora de grandes reflexiones, de hacer uso del intelecto para advertir los errores del pasado y del presente; de revisar conceptos y estrategias para el futuro; de no repetir las experiencias de otros países que -en el marco de disímiles situaciones políticas, económicas y 
sociales - manifiestan inhumanas condiciones de vida para segmentos de su población y diferentes pero significativas formas de deterioro del entorno humano. Es tiempo en fin, de armonizar economía con ecología, de recuperar y balancear las distintas facetas que hacen al bienestar humano porque es exclusivamente en beneficio de éste hombre de hoy y del mañana hacia donde deben estar dirigidos los esfuerzos.

\section{FAUNA}

\section{Eduardo P. Tonni - Hugo L. López}

La provincia de Buenos Aires posee rasgos naturales diversos dentro de su dilatada extensión. Sus límites, en su mayoría naturales, suelen ser vías de penetración y/o barreras para diferentes organismos.

La alta concentración urbana en algunas de sus regiones ha afectado seriamente sus áreas naturales, llegando a poseer algunos de sus cursos de agua, los más altos grado de contaminación del país.

La alteración ambiental afecta en forma directa a la fauna y de ahí a los procesos de extracción. En ambientes sobreexplotados la contaminación es un factor más que tiende a eliminar el recurso y consecuentemente producir un rápido deterioro económico, afectando principalmente a la comunidad regional.

Los estudios sobre los recursos faunísticos en la provincia de Buenos Aires, se han realizado bajo diferentes aspectos, ya sea a través de obras de índole general o de planes de investigación

que han tomado áreas puntuales del ámbito provincial. En la mayoría de los casos, estos esfuerzos se llevaron a cabo sin seguir un política clara sobre los recursos que conduzca a concretar un objetivo final dentro del contex to territorial de la provincia. 
La explotación de la fauna silvestre se ha realizado con escaso criterio científico ante la falta de un plan adecuado para el manejo del recurso. Ya Ringuelet y Arámburu en 1957 habían señalado que «...los censos de la fauna de un país o región cualquiera, constituyen una suerte de codificación de la naturaleza, como paso previo e indispensable para un ensayo racional de aprovechamiento de las riquezas naturales y de su adecuada conservación».

La temática de la conservación y manejo del recurso fauna puede considerarse bajo diferentes aspectos.

En los cuerpos de agua continentales de la provincia de Buenos Aires el recurso íctico tiene importancia económica, especialmente a nivel local o regional. Este puede verse amenazado por una extracción tanto comercial como deportiva sin control apoyado en estudios del ambiente y sus recursos. Por otra parte, la contaminación en los ambientes lacustres cobra singular importancia y dramaticidad principalmente en aquellos ubicados en las proximidades de centros urbanos donde el volcado de efluentes de diversos origen y sin tratamiento, es un hecho cotidiano y un factor de riesgo permanente. Sin embargo, aquellos biotopos acuáticos emplazados en áreas rurales, tampoco escapan a esta situación, puesto que el lavado de los fertilizantes y pesticidas utilizados en la explotación agrícola, afectan seriamente a las comunidades acuáticas.

Las aguas continentales tampoco han escapado a la penetración de especies exóticas que están alterando las asociaciones. Estas especies han sido generalmente introducidas sin estudios previos que determinen el impacto a producir en el ambiente. Un caso concreto en el ámbito bonaerense es la carpa, un cipriniforme de origen asiático que en poco más de 40 años ocupó zonas costeras del Río de la Plata y la mayoría de los sistemas fluviales y lacustres bonaerenses. Esta especie presumiblemente ha comenzado a desplazar al sábalo, la especie nativa de mayor biomasa en la cuenca Paranoplatense. Es obvio que el problema existe; la erradicación de la especie exótica no es posible, de manera tal que deberían buscarse las alternativas de 
aprovechamiento racional de este «nuevo» recurso. Este caso particular, señala la necesidad de implementar programas de piscicultura que utilicen a las especies nativas y a aquellas exóticas que se han adaptado al sistema.

La fauna silvestre de la provincia de Buenos Aires, no ha sido objeto de un proceso extractivo indiscriminado, excepto algunos casos (v.gr. Lobo marino). Sin embargo, ella no escapa a ls profundas alteraciones provocadas en el medio ambiente por la acción antrópica en sus diversas manifestaciones (densidad demográfica, explotación agropecuaria intensiva). Los pesticidas son utilizados para eliminar insectos "perjudiciales», pero coincidentemente producen la reducción de aves insectívoras, sea directamente por intoxicación o a través de la acumulación de ciertos pesticidas que provocan el debilitamiento de las cáscaras de los huevos y su inviabilidad. De esta forma, se elimina el factor natural de control y se introducen alteraciones en el ambiente por la incorporación de sustancias extrañas.

Otro aspecto a considerar es que en la mayoría de los casos se ha dejado de lado el aspecto integrador con que deben considerarse los sistemas naturales. Es frecuente que se ponga énfasis en la protección de ciertas especies que sufren un proceso extractivo y ese mismo énfasis no se vuelque en aquellas actualmente sin valor económico. Sin embargo, la extinción de cualquier especie quita diversidad a los sistemas y consecuentemente limita un futuro en el que esa diversidad sea la base de la explotación racional de los recursos naturales.

La provincia de Buenos Aires, una de las más estudiadas en cuanto a sus recursos naturales tienen, sin embargo, grandes áreas de su territorio - algunas de ellas ecotonales- sin una valoración adecuada de su fauna y relaciones. Ciertamente, el delta, el árido bonaerense y la cuenca del Salado, se encuentran en mayor o menor medida en estas condiciones. En este último caso, se han realizado esfuerzos de conjunto mayores que en los dos restantes, pero aún falta mucho por hacer, fundamentalmente si se consideran las alteraciones que puedan provocar las obras de desagüe actualmente implementadas. 
El medio ambiente no posee límites políticos. Es claro entonces, que esta breve enunciación de temas no es aplicable sólo a la provincia de Buenos Aires; quizá los aspectos particulares le son propios pero la temática es global. Ciertamente, la necesidad de una integración y programación de los estudios es imperiosa. El éxito o no de esta interacción podrá ser valorado en un futuro próximo. 